\title{
TU/e EmonONEN

\section{A football kicking high speed actuator for a mobile robotic application}

Citation for published version (APA):

Meessen, K. J., Paulides, J. J. H., \& Lomonova, E. (2010). A football kicking high speed actuator for a mobile robotic application. In Proceedings of the 36th Annual Conference of the IEEE Industrial Electronics Society, IECON 2010, 7-10 November 2010, Glendale, Arizona (pp. 1659-1664). Institute of Electrical and Electronics Engineers. https://doi.org/10.1109/IECON.2010.5675433

DOI:

10.1109/IECON.2010.5675433

Document status and date:

Published: 01/01/2010

\section{Document Version:}

Publisher's PDF, also known as Version of Record (includes final page, issue and volume numbers)

\section{Please check the document version of this publication:}

- A submitted manuscript is the version of the article upon submission and before peer-review. There can be important differences between the submitted version and the official published version of record. People interested in the research are advised to contact the author for the final version of the publication, or visit the $\mathrm{DOI}$ to the publisher's website.

- The final author version and the galley proof are versions of the publication after peer review.

- The final published version features the final layout of the paper including the volume, issue and page numbers.

Link to publication

\section{General rights}

Copyright and moral rights for the publications made accessible in the public portal are retained by the authors and/or other copyright owners and it is a condition of accessing publications that users recognise and abide by the legal requirements associated with these rights.

- Users may download and print one copy of any publication from the public portal for the purpose of private study or research.

- You may not further distribute the material or use it for any profit-making activity or commercial gain

- You may freely distribute the URL identifying the publication in the public portal.

If the publication is distributed under the terms of Article 25fa of the Dutch Copyright Act, indicated by the "Taverne" license above, please follow below link for the End User Agreement:

www.tue.nl/taverne

Take down policy

If you believe that this document breaches copyright please contact us at:

openaccess@tue.nl

providing details and we will investigate your claim. 


\title{
A Football Kicking High Speed Actuator for a Mobile Robotic Application
}

\author{
K. J. Meessen, J. J. H. Paulides, E. A. Lomonova \\ Eindhoven University of Technology \\ 5612AZ Eindhoven, the Netherlands \\ Email: k.j.meessen@tue.nl
}

\begin{abstract}
This paper presents the design and validation of a high speed reluctance actuator for a soccer robot. The actuator is used to shoot a regular sized soccer ball by applying different force levels directly to the ball. As the application requires force in only one direction, a plunger type reluctance actuator is selected. A capacitor is used to buffer energy from the battery of the robot. Through an IGBT, the energy is transferred from the capacitor to the actuator. Consequently, by applying pulse width modulation, the force applied by the actuator can be adjusted to enable a variable shooting power. The reluctance type actuator is designed using finite element analysis. The actuator is build and implemented in the robot providing the capability to shoot a ball from standstill over 12 meters with a starting speed of 11 $\mathbf{m} / \mathbf{s}$.
\end{abstract}

\section{INTRODUCTION}

RoboCup [1] is an international joint project to stimulate research in the field of artificial intelligence, robotics and related fields. A robot soccer game is used as the central topic where a wide range of technologies can be developed and integrated. To establish intelligent motion for autonomous robots, sensing, signal processing, decision making and actuation have to work properly. The large number of essential tasks that have to be integrated results in a complex system where obtaining robust performance is one of the main challenges.

The robots play soccer autonomously according to the FIFA rules with a list of modifications such that it is suited for state-of-the-art robotics. Several leagues exist where this paper concerns a robot for the mid-size league, i.e., a wheeled robot with a height of maximum $80 \mathrm{~cm}$ playing in a team of five on a field of $12 \times 18 \mathrm{~m}$.

This paper focusses on the shooting mechanism for a mobile football robot to shoot the ball with variable speed and over a variable distance. To define the system requirements very accurately, an extensive ball model should be taken into account which includes e.g. pressure, stiffness, mass and the ball material. Additionally, the exact position on the ball surface where the robot hits the ball affects the ball behavior. Therefore, experience from previous shooting devices as well as results from experiments (e.g. football games at european and world level, www.techunited.nl) are used to define the requirements. This has lead to the initial design requirement that the ball has to be shot with an initial speed of at least $10 \mathrm{~m} / \mathrm{s}$. Since the stroke of the actuator is limited due to the volumetric constraints of the complete robot, a very high acceleration level up to $1000 \mathrm{~ms}^{-2}$ is required dependent on

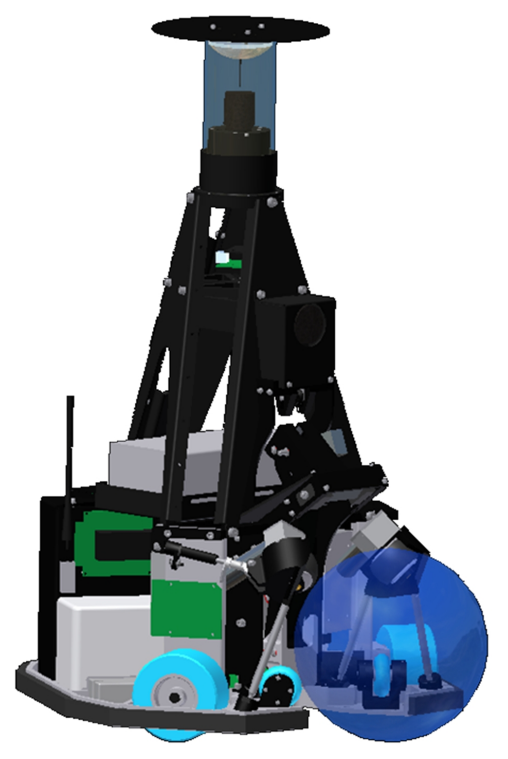

Fig. 1. Mobile soccer robot [2].

the moving mass. As the actuator is mounted on a moving platform, the total mass of the actuator should also be as low as possible. Furthermore, as the dimensions of the robot are limited, other geometric constraints also apply to the complete shooting mechanism (e.g. including power electronics, and capacitor).

Based on the aforementioned requirements, different linear actuator topologies could be implemented. However, the acceleration requirement already allows a pre-selection of the possible actuator topologies. As such, only direct-drive solution are considered to be implementable. Further, a high force density is required to minimize the mass, hence permanent magnet (PM) linear actuators are considered to be a promising candidate. In particular, linear tubular permanent magnet actuators are exploited to achieve very high force/acceleration levels [3], [4]. However, to achieve these high force density levels, linear actuators commonly use three phase windings which require full-bridge power electronics and commutation. Hence, position sensors are required and the total system is rather complex. Due to its relative simple structure and the absence of commutation and three phase power supply, also voice- 
coil actuators are considered to be a promising candidate. However, these actuators typically have a short stroke with limited force capability which is not considered to be sufficient for this application. An alternative is the reluctance actuator (solenoid), which combines "short-stroke" with a relative high force density and a very simple structure. Therefore, a plunger type reluctance actuator has been selected and designed for this application [5], [6].

In this paper, the design of the solenoid is presented as well as the driving circuit of the actuator. In Section II the requirements of the actuator are treated and in Section III the driving circuit is described. In Section IVb a magnetostatic finite element analysis (FEA) is provided to investigate the initial sizes. Section IVc presents the transient analysis which deals with the transient magnetic and electric behavior. Furthermore, this transient model is used to investigated the influence of the eddy currents on the performance of the system. The last section deals with the experimental verification of the actuator integrated in the robot.

\section{REQUIREMENTS}

From measurements on previous shooting mechanisms and simulations, the requirements of the solenoid are determined as stated in Table I.

TABLE I

REQUIREMENTS AND CONSTRAINTS

\begin{tabular}{lll}
\hline Property & Value & Description \\
\hline$S(\mathrm{~mm})$ & 80 & Minimum stroke \\
$L_{a x}(\mathrm{~mm})$ & 220 & Maximum actuator length \\
$D_{\max }(\mathrm{mm})$ & 95 & Maximum actuator diameter \\
$v_{f}(\mathrm{~m} / \mathrm{s})$ & 10 & Final velocity at end of stroke \\
\hline$U_{\text {peak }}(\mathrm{V})$ & 450 & Maximum allowable voltage \\
$I_{\text {peak }}(\mathrm{A})$ & 100 & Maximum allowable current \\
\hline
\end{tabular}

Besides the requirements concerning the force and sizes, the force produced by the actuator has to be repeatable and controllable. As the actuator is used to shoot a ball in a soccer game, it should be able to produce a high force when shooting at the goal and produce a lower force during a pass. To enable the use of standard electric components, electric constraints as listed in Table I have to be obeyed.

\section{DRIVING CIRCUIT}

The robot is equipped with two batteries of $24 \mathrm{~V}$ being the main power source of the robot. As the solenoid requires a very high peak power, a $450 \mathrm{~V} 4.7 \mathrm{mF}$ capacitor is selected to buffer the energy. The capacitor is charged from batteries and discharged over the solenoid using the circuit as shown in Fig. 2 where the inductance and resistance, $L, R$, represent the solenoid. Using the IGBT, the current through the coil can be adjusted. By using a pulse width modulation (PWM) signal to switch the IGBT, the force produced by the solenoid can be adjusted. To avoid voltage spikes over the IGBT when switching off, a flyback diode $D$ is placed in parallel with the solenoid. A DC/DC converter is used to charge the capacitor when the voltage over the capacitor is below a certain threshold.

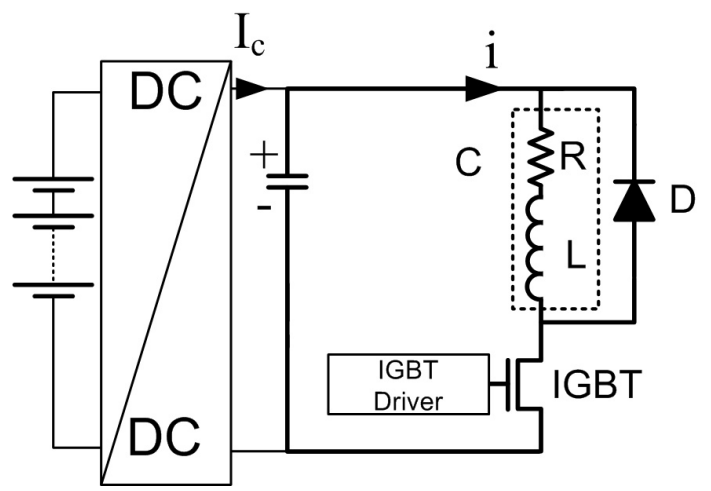

Fig. 2. Circuit used to drive the actuator.

When the IGBT is closed, the circuit can be considered as a damped oscillator described by the following second order differential equation

$$
L \frac{d^{2} i}{d t^{2}}+R \frac{d i}{d t}+\frac{1}{C} i=0 .
$$

A typical response of this circuit is shown in Fig. 3 where $T_{n}$ is the inverse of the damped natural frequency [7]. The damped natural frequency is defined by the components in the circuit by

$$
\omega_{d}=\sqrt{1-\zeta^{2}} \sqrt{\frac{1}{L C}},
$$

where $\zeta$ is the damping factor

$$
\zeta=\frac{R}{2 \sqrt{\frac{L}{C}}} .
$$

In the design of the actuator, these dynamics have to be taken into account to meet the requirements as listed in Table I. Firstly, $\frac{T_{n}}{2}$ should be in the order of the travel time of the mover through the coil because otherwise the capacity of the capacitor is only partly used. From the requirements the travel time can be estimated when the acceleration is assumed to be constant using

$$
\begin{aligned}
x_{f} & =\frac{1}{2} a t_{f}^{2} \\
v_{f} & =a t_{f} \\
t_{f} & =\frac{2 x_{f}}{v_{f}}
\end{aligned}
$$

where $x_{f}$ is the final traveled distance or stroke and $v_{f}$ is the velocity at the end of the stroke. This results in a travel time of approximately $16 \mathrm{~ms}$ and a constant acceleration of $625 \mathrm{~ms}^{-2}$.

Secondly, the peak current as shown in Fig. 3 should not exceed the maximum current as given in Table I. Hence, the resistance and the inductance of the actuator are of major importance in the design of the actuator. 


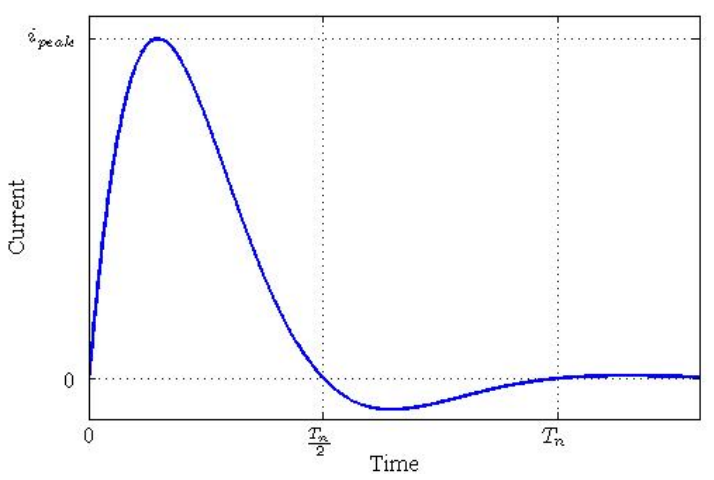

Fig. 3. Current through circuit when IGBT is closed.

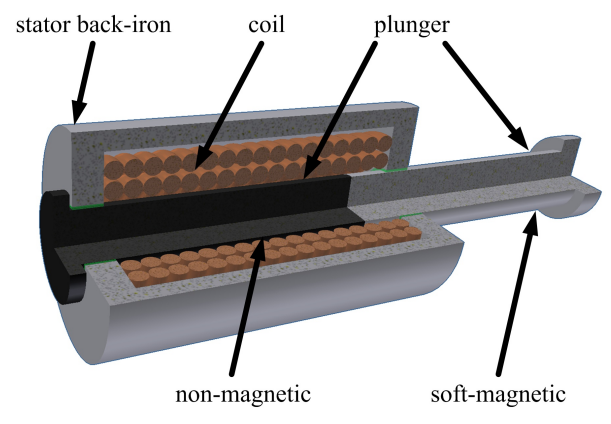

Fig. 4. Plunger type solenoid.

\section{ACTUATOR DESIGN}

The selected actuator topology is a plunger type solenoid as shown in Fig. 4. As can be seen, the cylindrical mover or plunger consists of a non-magnetic and a soft-magnetic part surrounded by a stationary cylindrical coil. By applying a current through the coil, the soft-magnetic part is retracted in the coil resulting in a one directional propulsion force. To be able to position the plunger in the correct position after a current is supplied, the actuator is placed slightly tilted in the robot.

\section{A. Thermal}

To investigate the thermal behavior of the actuator a worst case scenario approximation is used. Consider that the capacitor is fully charged to $450 \mathrm{~V}$, hence contains the following

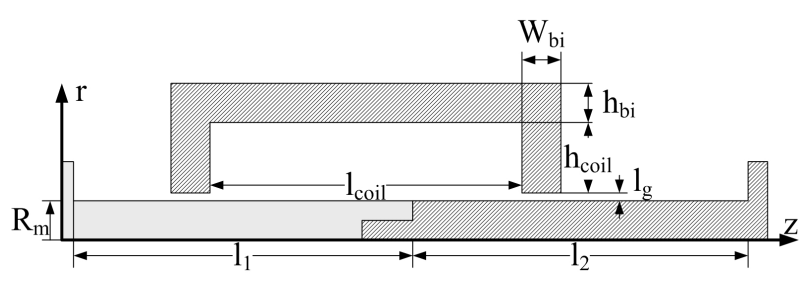

Fig. 5. Parameters describing the solenoid.

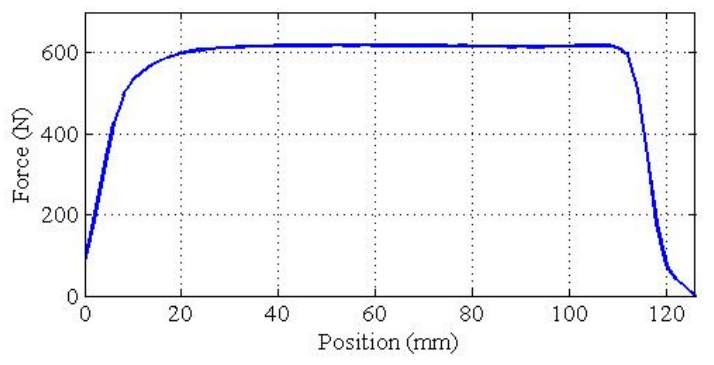

Fig. 6. Force versus stroke having constant current in the coil.

amount of energy

$$
\begin{aligned}
E_{C} & =\frac{1}{2} C V^{2} \\
& =476 \mathrm{~J} .
\end{aligned}
$$

The mass of the actuator is estimated to be at least $4.0 \mathrm{~kg}$ which is mainly copper and iron. The thermal capacity of $4.0 \mathrm{~kg}$ copper is $1540 \mathrm{JK}^{-1}$, and the thermal capacity of $4.0 \mathrm{~kg}$ iron is $1800 \mathrm{JK}^{-1}$. When all energy from the capacitor is transformed into heat, the actuator temperature rises only one third of a degree without taking into account the radiation and convection. Furthermore, fully charging the capacitor takes approximately 15 seconds, hence, the thermal limits of the actuator are not of a major concern here.

\section{B. Magneto-static}

For the initial sizing of actuator a magneto-static finite element model (FEM) is created [8]. An axis-symmetric model as shown in Fig. 5 is created in FLUX2D. The aim of this model is to investigate the minimum length of the coil to achieve sufficient force over the full stroke of at least $80 \mathrm{~mm}$. A model with the maximum volume as given in Table I, a mover radius of $12.5 \mathrm{~mm}$, a coil height of $22.0 \mathrm{~mm}$ and a coil length of $130 \mathrm{~mm}$ is created. The current density is increased from zero to a value which provides enough force to accelerate the mover with an acceleration of $650 \mathrm{~ms}^{-2}$ as mentioned before. The current density providing enough force is found to be $40 \mathrm{Amm}^{-2}$. Note that this value is only an initial value used in the analysis here, during the dynamic analysis, this value will change in time due to the dynamics of the electrical circuit. The initial position of the mover $z=0$ is just outside the coil, inside the back-iron. The mover is displaced through the coil until the mover is completely inside the actuator. The corresponding force versus position is shown in Fig. 6. As can be seen, the force increases until the mover is approximately $20 \mathrm{~mm}$ inside the coil. Subsequently it remains constant until the other side of the coil is reached at $z=110 \mathrm{~mm}$. Hence, the force is over $100 \mathrm{~mm}$ within $90 \%$ of its maximum value. Therefore, the axial length of the actuator can be decreased as a stroke of $80 \mathrm{~mm}$ is required.

To investigate the influence of saturation in the mover, a second model is created with the modified axial length. At different mover positions the force is calculated for several 
values of the current density in the range between 10 and $60 \mathrm{Amm}^{-2}$ resulting in flux density levels up to 3 Tesla in the mover. The produced force is divided by the applied current resulting in a linear function for all positions except the positions when the mover is almost completely inside the coil. Hence, when the effective airgap is larger than $10 \mathrm{~mm}$, the effect of mover saturation is negligible. Furthermore, the sizes of the back-iron are minimized to reduce the mass while avoiding too high saturation levels.

A third FE model is created with the adapted sizes from the aforementioned analysis results, e.g. a coil length, $l_{\text {coil }}$ of $110 \mathrm{~mm}$. In this model, the current density is again fixed at $40 \mathrm{Amm}^{-2}$. A parametric analysis is performed to investigate the influence of the parameter $h_{\text {coil }}$ on the inductance of the coil. For all values of $h_{\text {coil }}$, the inductance is calculated at multiple mover positions. Although the inductance of this type of actuator is heavily dependent on position and current due to saturation, a mean value of the inductance as function of $h_{\text {coil }}$ is calculated from the FEM model. This inductance value represents the inductance for a coil having a single turn, $L_{1}$ for a certain value of $h_{\text {coil }}$. The total inductance of the coil can subsequently be calculated using

$$
L_{N}=L_{1} N^{2}
$$

where $N$ is the total number of turns. The resistance of the coil is calculated using

$$
R_{N}=\rho_{C u} \frac{l}{A k_{f}} N^{2}
$$

where $\rho_{C u}$ is the resistivity of copper, $l$ is the mean length of a single wire of the coil, $A$ is the total coil area $l_{\text {coil }} \cdot h_{\text {coil }}$, and $k_{f}$ is the filling factor of the coil which is assumed to be 0.55 for an orthocyclic coil. By varying the number of turns, $N$, and the height of the coil, $h_{\text {coil }}$, the natural frequency (2) can be adjusted such that $\frac{T_{n}}{2}$ is approximately $16 \mathrm{~ms}$ without violating the constraint on the maximum current. At the same time the force needs to be maximized which is for this type of actuator given by

$$
\begin{aligned}
F & =-\left.\frac{\Delta W_{f}^{\prime}(z, i)}{\Delta z}\right|_{\lambda=\text { constant }}, \\
& =\frac{i^{2}(t)}{2} \frac{\partial L(z)}{\partial z},
\end{aligned}
$$

where $W_{f}^{\prime}$ is the co-energy and $i$ is the current through the coil which should not exceed the maximum current as given in Table I. On the other hand, the height of the coil $h_{\text {coil }}$ should be minimized to reduce the total actuator mass.

Using this information, an initial value for $h_{\text {coil }}$ and the number of turns are selected for the transient analysis.

\section{Transient}

Using the results from the magneto-static model, a full transient FE model is created to investigate the dynamic behavior of the actuator. The circuit as shown in Fig. 2 is implemented where a (stranded) coil conductor represents the actuator coil in the circuit. This provides the ability to
TABLE II

LOSSES IN THE ACTUATOR

\begin{tabular}{ll}
\hline Loss component & Energy \\
\hline Copper loss & $231.4 \mathrm{~J}$ \\
Eddy current back-iron (FEM) & $2.7 \mathrm{~J}$ \\
Eddy current soft-magnetic mover (FEM) & $5.7 \mathrm{~J}$ \\
Eddy current non-magnetic mover (FEM) & $13.9 \mathrm{~J}$ \\
\hline
\end{tabular}

include the dynamic behavior of the circuit in the FEA. The initial sizes and number of turns selected using the results of the magneto-static analysis are adapted such that the criteria as mentioned in the previous section are met including all dynamic effects.

A final FE model is created which includes the calculation of eddy current losses in three different parts of the actuator namely, the back-iron, the soft-magnetic part of the mover and the non-magnetic part of the mover. The back-iron encounters a time varying magnetic field solely due to the current while the mover experiences a time-varying field due to the current as well as the movement. The back-iron and the soft-magnetic part of the mover are made of (solid) iron (st 37.3, 1.0114). To withstand the mechanical stress when the mover collides with the ball, or with other objects, the non-magnetic part is made of aluminum instead of an electrically non-conducting material. The results from the FEA are shown in Table II. As can be seen the losses in the aluminum part of the mover are the most significant however, the losses are still much lower than the copper losses, the other loss component. To minimize the losses in the soft-magnetic parts of the actuator, normally laminated structures are used. However, lamination for these type of cylindrical actuators with an axial flux flow should have a wedge shape. To create a robust mechanical structure from these type of wedge shaped parts will be difficult. Therefore, the final design contains solely solid steel parts. Having these type of materials, the requirements are still met.

\section{Final design}

From the preceding sections, a final design as shown in Fig. 7 is obtained with the dimensions as listed in Table III. The stroke of the actuator is increased by $5 \mathrm{~mm}$ to be able to include a rubber end stop. The soft-magnetic and the non-

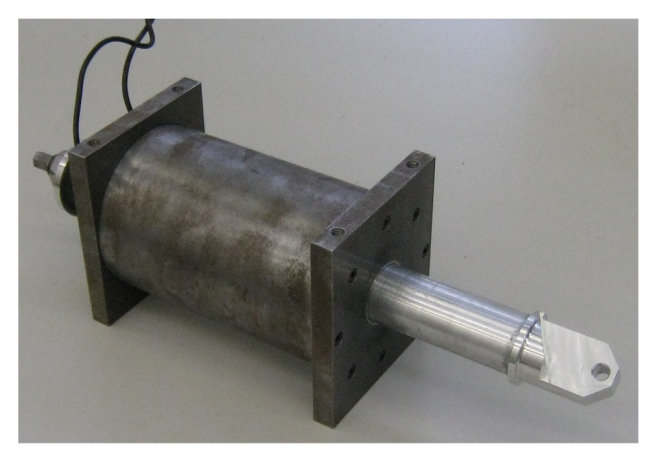

Fig. 7. Prototype of the final design of the actuator. 


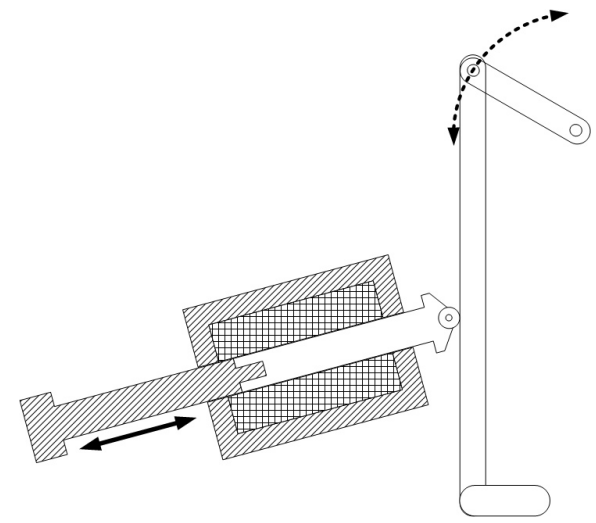

Fig. 8. Actuator including shooting mechanism.

magnetic part of the mover are connected using a (softmagnetic) thread as is also visible in Fig. 5. In the airgap in the back-iron, a thin coated brass cylinder is mounted as sliding bearing. The capacitor which is rated for a voltage up to $450 \mathrm{~V}$ is charged using a DC-DC converter up to $435 \mathrm{~V}$.

TABLE III

DIMENSIONS FINAL DESIGN

\begin{tabular}{lll}
\hline Property & Value & Description \\
\hline$S(\mathrm{~mm})$ & 85 & Stroke \\
$l_{1}(\mathrm{~mm})$ & 105 & Length non-magnetic plunger \\
$l_{2}(\mathrm{~mm})$ & 110 & Length soft-magnetic plunger \\
$l_{g}(\mathrm{~mm})$ & 1.0 & Airgap length \\
$l_{\text {coil }}(\mathrm{mm})$ & 110 & Coil length \\
$h_{\text {coil }}(\mathrm{mm})$ & 17.5 & Coil height \\
$h_{\text {bi }}(\mathrm{mm})$ & 7.0 & Back-iron height \\
$w_{\text {bi }}(\mathrm{mm})$ & 10.0 & Back-iron width \\
$R_{m}(\mathrm{~mm})$ & 12.5 & Mover radius \\
$m_{\text {mover }}(\mathrm{kg})$ & 0.69 & Mover mass \\
$m_{\text {total }}(\mathrm{kg})$ & 4.5 & Total actuator mass \\
\hline$U_{\text {peak }}(\mathrm{V})$ & 435 & Capacitor voltage \\
$I_{\text {peak }}(\mathrm{A})$ & 100 & Maximum allowable current \\
$R(\Omega)$ & 2.4 & Coil resistance \\
$N(-)$ & 1050 & Number of turns \\
\hline
\end{tabular}

\section{EXPERIMENTAL VERIFICATION SYSTEM}

\section{A. Shooting mechanism}

As described in the introduction, the actuator is applied in a mobile soccer robot. The mover of the actuator is connected to a lever to provide contact with the ball as shown in Fig. 8. By moving this lever up and downwards, the contact point with the ball during the collision is moved up or downwards as well. This degree of freedom provides the ability to shoot the ball with a given angle with respect to the ground. The range of the initial angle provided by the system is between 0 and 38 degrees.

\section{B. Measurements}

The performance of the actuator is verified by conducting measurements on the system. The measurements are compared with the results of the dynamic non-linear FE model including eddy currents. Initially all measurements are conducted for two different conditions:

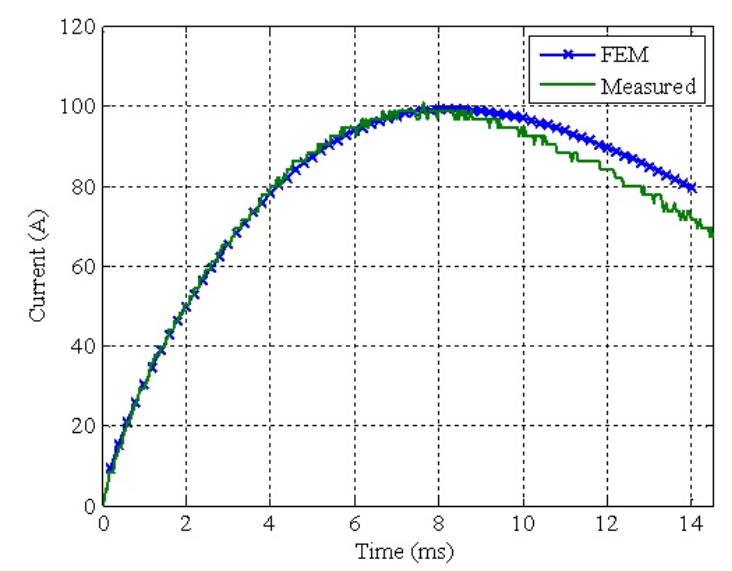

Fig. 9. Current through coil, measured and simulated using FEA.

1) Without load; a full shot (dutycycle of 100\%) without ball

2) With load; a full flat shot (dutycycle of 100\%) with ball

Using an acceleration sensor on the mover the acceleration is measured while the current is monitored. Fig. 9 shows the current through the coil versus time. As can be seen, the waveform is similar to the one shown in Fig. 3. The current calculated in the FEA and the measurement are initially in agreement while in the last part of the pulse the measured current is slightly lower. The constraint that the current does not exceed $100 \mathrm{~A}$ is satisfied.

In Fig. 10, the measured acceleration is shown for the two cases, with and without ball. As can be seen the acceleration profile follows the current profile of Fig. 9 in case of no load. Without the ball, the mover is continuously accelerating until $t=14.8 \mathrm{~ms}$, at that time the mover hits the end stop. When the ball is used as a load for the actuator, the acceleration profile is initially the same. After approximately $3 \mathrm{~ms}$, the ball is hit by the mover and the acceleration is less than in case of no load. As the ball initially acts as a spring, the acceleration decreases slowly. After a while, the load of the actuator is that significant that the mover starts to decelerate due to the mass and the spring stiffness of the ball at $t=11.5 \mathrm{~ms}$.

As the FE model does not include the spring characteristic of the ball, the model represents only the no-load case. Fig. 11 compares the measured and the modeled acceleration. The waveform and the peak value are in agreement although initially the measured acceleration lags with the simulated acceleration. This effect is caused by a non-linear effect in the actuator which is not included in the FE model.

From the measured acceleration, the velocity of the mover is obtained by numerical integration. The result is shown in Fig. 12. As can be seen, without the ball the velocity increase up to approximately $11 \mathrm{~m} / \mathrm{s}$ at $t=14.8 \mathrm{~ms}$. In case the ball is used as load, the velocity rises but is decreased due to the ball. At the end of the stroke when the ball is shot, the mover has a speed of $3 \mathrm{~m} / \mathrm{s}$. Comparing the no-load velocity of the measurement and the FEA, a small discrepancy can be seen. 


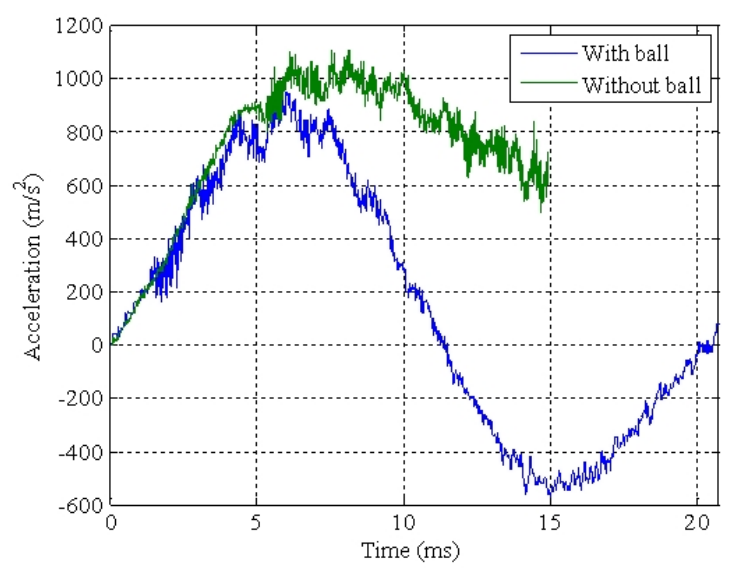

Fig. 10. Mover acceleration measured with and without ball as load.

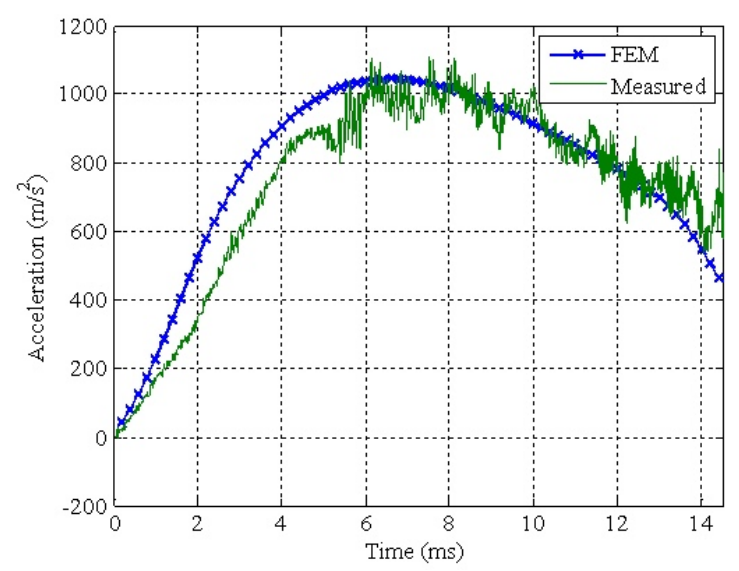

Fig. 11. Mover acceleration without ball, measured and simulated using FEA.

As was also concluded from Fig. 11, a non-linear effect is not included in the FE model resulting in a measured velocity which is lower than the simulated value.

\section{Shooting power}

Using a high speed camera and a model of the ball, the movement of the ball is analyzed during a lob shot. The initial speed of the ball as well as the point where the ball hits the

TABLE IV

SHOOTING PERFORMANCE

\begin{tabular}{lll}
\hline Dutycycle & Distance $(\mathrm{m})$ & Initial speed $(\mathrm{m} / \mathrm{s})$ \\
\hline 0.2 & 2.5 & 5.0 \\
0.3 & 3.7 & 6.1 \\
0.4 & 5.1 & 7.0 \\
0.5 & 6.0 & 7.9 \\
0.6 & 7.5 & 8.6 \\
0.7 & 8.9 & 9.3 \\
0.8 & 10.1 & 10.0 \\
0.9 & 11.2 & 10.5 \\
1.0 & 12.2 & 11.2 \\
\hline
\end{tabular}

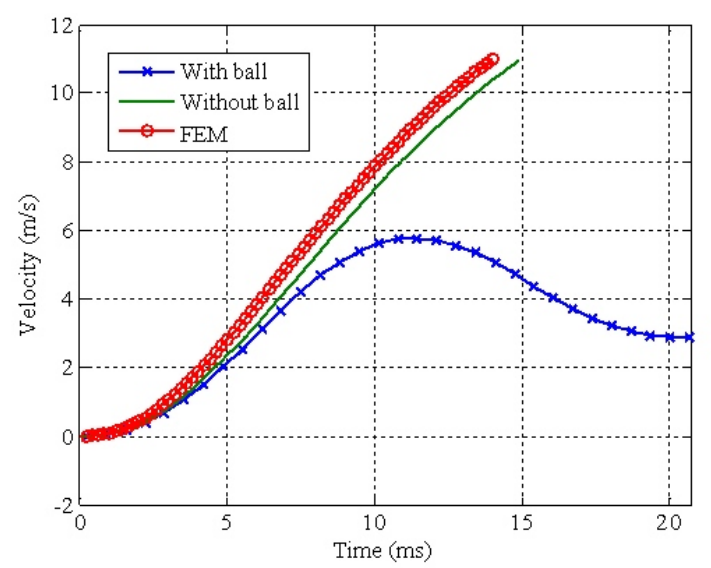

Fig. 12. Mover speed without ball, measured and simulated using FEA.

ground during a lob shot are obtained for different PWM duty cycles. The results of this measurement are listed in Table IV. The distance represents the distance from the center of the robot to the point where the ball hits the ground for the first time. The relation between the position and the duty cycle is very linear however very dependent on the ball. The mass and the pressure (hence stiffness and damping) of the ball are of major influence on the movement of the ball through the air.

\section{CONCLUSIONS}

A high speed linear reluctance actuator is designed for a mobile soccer robot. A plunger type actuator is selected because of its robust structure and the possibility of a simple power supply. Using finite element analysis, the actuator is designed such that all requirements are met and the mass of the actuator is minimized. The designed actuator is manufactured and built in a robot. The actuator performance is verified by measuring the current and the mover acceleration during no load and load conditions. The results are compared with a FE model and show good agreement. Further, the shooting results of the robot are analyzed by measuring the ball movement while the shooting power is adjusted using PWM.

\section{REFERENCES}

[1] The RoboCup Federation, "Robocup."

[2] University of Eindhoven Robocup Team, "Techunited, http://www.techunited.nl."

[3] N. Jakeman, W. Bullough, C. Binghama, and P. Mellor, "Brushless pm linear actuator for high acceleration textile winding applications," International Journal of Applied Electromagnetics and Mechanics, vol. 19, pp. 237-242, April 2004.

[4] K. J. Meessen, J. J. H. Paulides, and E. A. Lomonova, "Analysis and design of a slotless tubular permanent magnet actuator for high acceleration applications," Journal of Applied Physics, vol. 105, p. 07F110, March 2009.

[5] C. R. Underhill, "Solenoids," American Institute of Electrical Engineers, Transactions of the, vol. XXXIII, pp. $477-517$, jan. 1914.

[6] B. Lequesne, "Finite-element analysis of a constant-force solenoid for fluid flow control," Industry Applications, IEEE Transactions on, vol. 24, pp. $574-581$, jul/aug 1988.

[7] W. J. Palm, Modeling analysis and control of dynamic systems. John Wiley and Sons, 1994.

[8] Cedrat, Meylan, France, FLUX2D 10.3 User's guide, 2010. 